\title{
What Do You Think about INVALSI Tests? \\ School Directors, Teachers and Students from Lombardy Describe Their Experience
}

\section{Giulia Pastori - Valentina Pagani}

Università degli Studi di Milano-Bicocca-Department of Human Sciences (Italy)

doi: 10.7358/ecps-2016-013-past

giulia.pastori@unimib.it

valentina.pagani@unimib.it

\section{COSA PENSATE DEI TEST INVALSI? DIRIGENTI SCOLASTICI, INSEGNANTI E STUDENTI PROVENIENTI DALLA LOMBARDIA DESCRIVONO LA LORO ESPERIENZA}

\section{Abstract}

The qualitative study "Promoting the culture of evaluation at school. The INVALSI experience at school» conducted between 2011-2012 by a research team from the University of Milan-Bicocca collected the ideas, opinions and perceptions of school actors on the INVALSI learning assessment experience. Adopting a "multi-vocal perspective», through individual and focus group interviews the viewpoints of different stakeholders within each school (nr. 16) have been examined: school directors (nr. 12), teachers of all grade levels (nr. 106) - some of them referents for the INVALSI evaluation in their school, and middle and high school students (nr. 100) who took INVALSI tests three or four times during their school career. The interpretative hypothesis, confirmed by the present study, considered that the organizational and communication procedures implemented by INVALSI, before and during test administration and correction, and especially during the process of returning the results, have important effects on the perceived quality of national evaluation in schools, on how the tests are proposed to students by school directors and teachers, and ultimately on the students' attitude towards the tests. The experiences collected in this study seem to mirror the antinomy described in literature between accountability and program evaluation, social 
control and social development objectives. Results highlight the complexity in combining those different approaches, accountability, reflection and self-assessment within the school from a coherent, systemic and procedural viewpoint.

Keywords: Qualitative data, School quality, Standard-based evaluation, Student voice, Teacher voice.

\section{InTRODUCTION}

What do school directors, teachers and students think about the national INVALSI evaluation system? What do the critical and sceptical attitudes echoed in the press depend on? How do you explain these attitudes, when over last decades international learning outcome surveys have triggered lively political and scientific debates and opened interesting areas of research? Is there any positive feedback?

The research project «Promoting the culture of evaluation at school. The INVALSI experience at school», conducted by a research team from the University of Milan-Bicocca ${ }^{1}$, involved school directors, teachers and students from primary, middle and high schools in individual and group interviews aimed at reflecting on and discussing on the learning assessment experience through standardized tests launched in recent years by INVALSI.

Important changes have been introduced over the last decade with the start of a regular survey of learning assessment through standardized tests, experimental projects to promote school quality (VSQ, Valorizza, Vales, Valsis ...) and the creation of the national assessment system.

On the one hand, this change has been encouraged by the importance and diffusion gradually acquired by international studies on evaluation and the comparison of school systems (Schleicher, 2011). International comparative surveys are now an integral part of the debate regarding schools in Italy, and they currently involve a growing number of countries (the last PISA study in 2012 tested the skills of 15-year-old students in mathematics, science and reading in 65 countries). Since the early 90 s, the OECD has regularly published a comparative report on education systems (Education at a glance).

1 Scientific supervisor: Susanna Mantovani and Elisabetta Nigris (University of MilanBicocca). The study is part of a wider research promoted by the School Office (USR) of Lombardy - «Report on School in Lombardy» -, in collaboration with Politecnico of Milan and University of Pavia: T. Agasisti, G. Catalano, \& G. Vittadini (a cura di), Rapporto sulla scuola in Lombardia. Strumenti di analisi e di policy, Milano: Guerini, 2013. 
On the other hand, at the national level, a system of school autonomy (W.59/1997) has been established which encourages the development of a system for monitoring the quality of school education throughout the national territory (Bottani \& Cenerini, 2003; Cerini, 2012).

These forms of national and international evaluation of the school system and studies related to them seem to offer the opportunity to start improvement processes within schools, providing parameters for comparison between schools distributed throughout the country, encouraging going beyond self-referentiality and excessive contextual relativity of the evaluation, and enabling comparisons between countries with internationally shared learning standards.

However, during these first years of experimentation and implementation of a national assessment system, there was perplexity in schools, even resistance and opposition (Corsini \& Losito, 2013), which were echoed in the press. The motivations behind these reactions have not received sufficient attention from researchers, although they are a field of study of great importance and sensitivity, in the effort to create an evaluation system with overall systemic validity that involves key players in the school context.

International studies reveal how the idea of the moment of evaluation and how it is perceived, creates the meaning of the evaluation event and its relationship with the context (Entwistle \& Entwistle, 1991; Brown \& Hirschfield, 2008). In this study, the privileged perspective of research focused on the processes which involved in the subjects experiencing the evaluation event, their ideas and experience of them, the effects they have (in terms of organization, relationships, reflective practices, teaching) at school, rather than on the products (namely the test results).

Specifically, we investigated the viewpoint of teachers, school directors and students on the procedural system implemented by INVALSI and the schools themselves, regarding critical and functional aspects: the organizational processes, communication, training and information, involving schools during period prior to test administration (preparatory phase); during test administration (operational phase) and in reading and using the results (restitution and results-reading phase).

The interpretative hypothesis, which emerged during the pilot phase and was confirmed by the present study, considers that the organizational and communication procedures implemented by INVALSI, before and during test administration and correction, and especially during the process of returning the results, have important effects on the perceived quality of national evaluation in schools, on how the tests were proposed to students and families by school directors and teachers, and ultimately on the students' attitude towards the tests. 


\section{Characteristics OF THE STUdy}

The qualitative study was conducted in Lombardy (2011-2012) and involved 16 public schools located in the city of Milan and the province. The schools were selected in order to represent all levels and the main types of high schools, with different student populations in terms of socio-economic status and citizenship.

\subsection{Participants}

Adopting a multi-vocal perspective, through individual and focus group interviews we examined the viewpoints of different actors within each school (see Table 1): school directors (nr. 12), teachers of all grade levels (nr. 106) - some of them referents for the INVALSI evaluation in their school, and middle and high school students (nr. 100) who took INVALSI tests three or four times during their school career. We chose to consult them because students are directly affected by school quality and, above all, they are extremely sensitive to the evaluation procedures. In fact, as recent studies have pointed out (Ruddock \& McIntyre, 2007; Czerniawski \& Kidd, 2011; Grion \& Cook-Sather, 2013; Pastori, 2013), although their voices are often silent and unheard, students represent key and specific informants on school quality and especially on evaluation (Hattie \& Timeperley, 2007). Their point of view, therefore, may be a powerful highlighter, emphasizing significant features of the INVALSI evaluation experience in schools (Struyven, Dochy, \& Janssens, 2005).

\subsection{Objectives}

The objectives of this study were:

- to elicit ideas, opinions and perceptions of the various stakeholders regarding the procedures implemented by INVALSI;

- to identify the main problems and the functional aspects, as perceived by stakeholders, regarding organizational processes, communication and training involving schools before the administration of the tests (preparatory phase); during the administration of the tests (operational phase) and in reading and using the results (restitution and results-reading phase);

- to offer, starting from the voices of participants, some suggestions for improving the current evaluation procedures. 


\subsection{Method and instruments}

The study used a qualitative approach, since it allowed participants' rich and meaningful experiences, ideas and opinions to emerge.

In particular, semi-structured interviews were proposed with school principals and evaluation representatives. Teachers and students were involved in focus group interviews, which intended to bring out the opinions of respondents and encourage comparison among different points of view (see Table 1).

Table 1. - Participants involved and instruments used.

\begin{tabular}{|c|c|c|c|c|}
\hline $\begin{array}{r}\mathrm{P} \\
\text { RESPO }\end{array}$ & $\begin{array}{l}\text { ICIPANTS/ } \\
\text { NTS INVOLVED }\end{array}$ & $\begin{array}{c}\text { Number } \\
\text { OF PARTICIPANTS/ } \\
\text { Respondents }\end{array}$ & $\begin{array}{l}\text { INSTRUMENTS } \\
\text { USED }\end{array}$ & $\begin{array}{c}\text { Number } \\
\text { OF INTERVIEWS }\end{array}$ \\
\hline School & School Institute* & 4 & $\begin{array}{l}\text { Semi-structured } \\
\text { individual interviews }\end{array}$ & 4 \\
\hline directors & High school & 8 & $\begin{array}{l}\text { Semi-structured } \\
\text { individual interviews }\end{array}$ & 8 \\
\hline & $\begin{array}{l}\text { Evaluation } \\
\text { representatives }\end{array}$ & 13 & $\begin{array}{l}\text { Semi-structured } \\
\text { individual interviews }\end{array}$ & 13 \\
\hline & $\begin{array}{l}\text { Primary school } \\
\text { teachers }\end{array}$ & 28 & $\begin{array}{l}\text { Focus group } \\
\text { interviews }\end{array}$ & 4 \\
\hline Teactivis & $\begin{array}{l}\text { Middle school } \\
\text { teachers }\end{array}$ & 28 & $\begin{array}{l}\text { Focus group } \\
\text { interviews }\end{array}$ & 4 \\
\hline & $\begin{array}{l}\text { High school } \\
\text { teachers }\end{array}$ & 37 & $\begin{array}{l}\text { Focus group } \\
\text { interviews }\end{array}$ & 6 \\
\hline & $\begin{array}{l}\text { Middle school } \\
\text { students }\end{array}$ & 43 & $\begin{array}{l}\text { Focus group } \\
\text { interviews }\end{array}$ & 4 \\
\hline stucents & $\begin{array}{l}\text { High school } \\
\text { students }\end{array}$ & 57 & $\begin{array}{l}\text { Focus group } \\
\text { interviews }\end{array}$ & 6 \\
\hline
\end{tabular}

* A School Institute (Istituto Comprensivo) is a primary and a middle school directed by the same principal.

The three salient core themes (consistent with the objectives of the study) around which semi-structured interviews and focus groups were constructed concerned:

1. how INVALSI organizes, communicates and gives information regarding the evaluation:

a. during the preparatory phase, before the administration of the tests; 
b. during the operational phase, during the administration, correction and tabulation of results;

c. during the restitution and results-reading phase;

2. communication modes regarding tests and results, within the school with families and students;

3. proposals that different stakeholders would advance if they could participate in a consultation with INVALSI.

A content analysis of the interviews was conducted. This phase involved the preparation of a report for each interview and focus group with a partial transcript of the recording. The data was organized using software for storing and encoding qualitative data (HyperResearch). In particular, the following themes were analyzed:

a. contents common between all actors;

b. contents and opinions specific to each of the various categories of subjects (school directors, teachers, students);

c. specific contents and opinions of the subjects with respect to the type of schools;

d. continuities and differences in opinion among participants at the same school.

\section{AN OVERVIEW: "A STRANGER AT HOME»}

Despite the general interest towards the INVALSI evaluation, especially for its objectivity, expressed by most of the research participants (84\%), 78\% of the respondents portray this experience as foreign, distant or unconnected to the daily school life and $81 \%$ of them use terms such as nonsense, uselessness and irrelevance to describe it.

In this scenario, the metaphor proposed by a high school teacher who defined the INVALSI tests as «a stranger at home» - a stranger who speaks an unknown language, who knocks on the door and sits in the classroom, observing class life for a day with a strange and unknown gaze and then, without giving any explanation, goes away - seems to effectively summarize a dominant pattern across the 16 schools involved in the research.

The analysis of the continuities and differences among participants within the same school highlights some variations and three main patterns:

- in 3 schools all the actors interviewed expressed a coherent negative opinion of the INVALSI experience;

- in 13 schools we observed a discontinuity of opinions: while school directors or teacher-referents showed interest and quite a positive attitude towards the INVALSI tests, teachers from the same school were unin- 
volved, disinterested or skeptical, and students expressed strong criticism, echoing or even exacerbating teachers' comments;

- only in one School Institute (Istituto Comprensivo) the viewpoints of the different actors resulted consistent and overall positive to this experience, judged as an enriching opportunity for the school.

Level and type of school didn't represent a meaningful descriptive variable, though it will be possible to highlight specific nuances of the participants' discourse, especially in reference to the school level.

Overall, research participants' voices corroborated the initial hypothesis that the process plays a crucial role in determining the perception and representation of the INVALSI evaluation experience. Below we mention some of the main elements of this process, from the preliminary stage to the final results-returning phase, as perceived and described by our interviewees.

\section{TEACHERS AND SCHOOL DIRECTORS' VOICES}

\section{1. "Organizational information is clear and timely ... but it's not enough"}

All the school directors, teacher-referents of the evaluation and most of the teachers declare that the information received prior to administration of the tests was sufficient, clear and timely from the organizational point of view:

All the information necessary to implement the procedure: the administration manual, the sequential order of the tests, the timing, methods, and so on ... everything is on the website. (SD $\left.{ }^{2}, \mathrm{IIg}\right)$

The on-line information enables the test administration, even in high schools, where tests were introduced in the last three years. However it is not enough.

Despite widespread appreciation for the clarity and amount of information, there are still some communication, information and organizational process issues that together undermine the experience.

\subsection{A bureaucratic top-down model}

A criticism reported by respondents and particularly by the teachers concerns the communication style adopted by INVALSI, perceived as highly bureau-

2 Adopted abbreviations: Type of respondent $\mathrm{SD}=$ School Director; TR $=$ Teacher-referent; $\mathrm{T}$ = Teacher; $\mathrm{St}=$ Student. Level of school: $\mathrm{Pr}=$ Primary school; Ig = Middle school; IIg = High school. 
cratic and unidirectional: «communication is always top-down: they tell you what to do, you do it» (T, IIg).

The teachers interviewed complain that INVALSI expects them to act as mere executors, without involving schools more significantly. In relation to this, the lack of teachers' education about the value of the tests and the procedures themselves is reported, regarding which teachers feel a strong need:

They give us the manual, we have to read it and then we administer the tests.

Period. There is no room for discussion. (T, Pr)

This would confirm that the INVALSI evaluation is only a big, rigid bureaucratic machine, far from the demands and needs of schools. The perceived rigidity is well exemplified by the experience of two schools (both licei classici): teachers from those schools told us that they had requested INVALSI to change the test dates due to previously scheduled class trips, and they "crashed into a wall: we were not allowed to move the date of the test» ( $\mathrm{T}$, IIg).

The spontaneity of this request and the respondents' genuine amazement tell us about the lack of understanding of the experimental nature of the tests and the resulting constraints and conditions that INVALSI necessarily asks regarding administration. Another gap on the informational level is evidenced: the lack of information about the characteristics of the tests and the purpose of the evaluation.

\section{3. "Little information on the characteristics of the tests: what do they have to do with everyday school?"}

The INVALSI evaluation appears foreign, since it is top-down, imposed and never negotiated, but also the characteristics of the tests contribute to fueling this feeling. The tests, inspired by the model of international learning assessment OECD-PISA, are unusual in the Italian school context. Not only are questions and problems formulated differently from those generally proposed by teachers and textbooks, but also the content and skills assessed do not seem to consistently connect to the ministerial guidelines of the school subjects.

This gap regarding everyday school raises questions and doubts within the schools and among teachers who would like to understand how and why these tests are constructed with a certain type of questions. The information provided by INVALSI does not seem to be sufficient, in particular for teachers, at all levels of school:

There are no problems on the organizational aspects, more than information, we probably needed teacher training. We felt a lack of training, precisely ... 
somebody who ... or even meetings in which one could speak, could express their doubts, but with someone who respond to these things. (T, Ig)

We do not have the tools to work in line with the INVALSI guidelines. (T, Ig)

I wish the reasoning behind certain questions was explained, because I can't see it. ( $\mathrm{T}, \mathrm{IIg})$

\subsection{Ambiguous purposes: who is under evaluation?}

One of the most important problems, reported almost unanimously, is the lack of information regarding the purpose of the tests and the characteristics of a national survey:

There is no clarity regarding the objectives. The perceived futility is also linked to the lack of clarity about goals and objectives. (T, IIg)

On the website, which is always very up to date, all the information necessary for the organization of the tests is available. There is also a telephone number and e-mail to refer to in case you need to communicate with INVALSI. Clarity about the purpose of INVALSI is lacking: it is not well specified. Maybe they take it for granted, because maybe at the beginning, perhaps when this activity was started, let's say this data collection, they may have shown some ... actually, their purpose, however, it is not well specified. In the sense that we ourselves do not understand what the validity of this assessment actually is. (TR, Ig)

Purpose? This has remained gray ... the State proposes them but after nothing happens. (SD, IIg)

Ambiguity and the lack of clarity regarding the ultimate goals of this great organizational machine generate anxieties and fuel doubts, also reported in the literature (Corsini, 2013; Corsini \& Losito, 2013), that this assessment is aimed at evaluation of teachers and schools:

The experience was confusing and the reasons given by teachers against the tests, in my opinion, were not always consistent: the teachers believed that the tests served to evaluate the teachers, or the school, but we are a school with a certain catchment area and we would have worse results than others. The fact of being evaluated generated much criticism. (SD, IIg)

I am glad that finally the concept of assessment has entered schools. I am a little less happy when they said that they're thinking of using INVALSI as evaluation of schools and teaching. The Ministry's attempt to evaluate teachers through children's acquisition of knowledge, I mean, since almost no teacher has confidence in the Ministry and they must know it, they must know when 
it comes to teacher evaluation that there is obviously an outcry. I am favorable,

but I know I'm a rarity. (TR, Pr)

The trace of a hidden, undeclared assessment, that is unfair, because it is not possible to measure the skill of a teacher based on the results of students (especially when the tests are so far removed from those used in the school), further foments mistrust and suspicion.

\subsection{The results are not easily accessible: little impact on school life}

The restitution phase is the one that would show more clearly the inefficiencies of the national evaluation system coordinated by the INVALSI institute.

Five of the 16 schools involved (3 high schools, one primary and one middle school) report that they never received the results.

However, even those schools that received them state that the results arrived «too late»: too late to read them and still recall the test and its correction; too late to give feedback to the students, offering them an opportunity to discuss and learn from their mistakes.

Besides this belated restitution, many school directors, teacher-referents and teachers recognized that they encountered some difficulties in understanding the results:

Honestly, I had some trouble, I saw too many graphics. (T, Ig)

Regarding the interpretative apparatus, I mean, the data is returned unprocessed. It would probably be helpful if instead INVALSI made an effort to offer some guidelines for the interpretation of this data. (SD, I and IIg)

The limited usefulness of the results had an impact at different levels.

First, it severely limited the effects of this evaluation, which nonetheless required teachers to devote their effort and time without being paid. Without ease of interpretation, the teachers failed to understand what they could draw from INVALSI reports in order to improve the effectiveness of their everyday teaching practices: «I'd like to know how my pupils performed and what mistakes they made, in order to understand what I need to work on, how I can improve myself» (T, Ig).

Secondly, the difficulty in reading the reports was also reflected in the lack of feedback to students. Communication with students and attention devoted to these tests assumed different forms: in primary schools teachers try to motivate students in a serene climate; in middle schools students are called upon to show commitment and seriousness (also due to the presence of INVALSI tests at the final State Examination); in high schools, the test 
presentation is very brief and, unlike at the lower educational levels, activities to prepare students for the tests are not usually provided. However, across all class levels there was a common failure to present and discuss the results with students: «after the administration of the tests the matter was closed: they were no longer mentioned» (T, IIg). Teachers, moreover, didn't seem to acknowledge the importance of this feedback for the students, who, as emerged in the focus group interviews dedicated to them, saw the absence of feedback as one of the main critical points of this experience.

\subsection{The critical issues perceived by the teachers reflect on students}

The extent to which teachers understand the goals of this evaluation and the criteria governing a statistical survey inevitably affect communication with students. Therefore, the communicational gap may mirror the lack of clear information and training that the teachers themselves related:

I think that teachers don't have a clear picture of these goals. It is as though INVALSI evaluation was something alien to the assessment carried out at school. (SD, I and IIg)

Incorrect information, combined with the insidious ghost of assessment, affects how some teachers present these tests to students and often fuels a vicious circle of mistrust and lack of motivation:

The more the teacher was informed, the more she could engage the class. The value we gave to the tests affected the value given by pupils. In our school pupils greatly depended on the teacher. (T, IIg)

If the teacher believed in [this evaluation] and motivated [the students], they complained in silence, otherwise in a loud voice. (SD, IIg)

This influence is moreover confirmed by the students themselves, who recognize that their opinions inevitably mirror the teacher's.

\subsection{Beyond criticism}

Overall, the experiences collected paint a rather grim picture of the INVALSI evaluation. However, despite the widespread criticism, the culture of evaluation within schools is not rejected tout court («I reckon that there should be an evaluation system in Italian schools»- T, IIg) and there are even positive opinions that highlight the enhancing opportunities that the INVALSI experience offers to schools. 
In particular, the INVALSI evaluation - objective and extended nationwide - is considered a first, fundamental step in overcoming self-referentiality:

[It is] definitely positive, it has rightly become mandatory. (DS, IIg)

I think that the process started by INVALSI is useful, it obliges us to introduce more objective evaluations and provides a picture of schools that can be compared to the national and regional averages. Otherwise, schools run the risk of absolute self-referentiality. This [evaluation] facilitates the identification of strengths and weaknesses on which the school can work. (SD, I and IIg)

There is no school autonomy without a system that allows you to account for what you are doing; otherwise we are in the purest self-referentiality and total anarchy. (SD, I and IIg)

I am quite favourable, because it is the only yardstick available at the national level, at a broad level. (TR, IIg)

It is also a valuable opportunity for teachers to reflect on their teaching practices; a stimulus for exchanging ideas with colleagues and for continuous self-improvement:

It is important to understand that we have to enhance what students can do and the tests may show that, rather than pointing the finger at what they don't know, giving them poor grades. The INVALSI tests therefore promote a reflection with this aim. (T, IIg)

These tests can be an opportunity for personal growth and maturation for students, called to face requests they are not accustomed to:

For my part, I have always been accustomed to question myself, hence I always try to figure out where my limits lie. [...] An external test, unrelated to the curricular program, could be useful to stimulate changes, improvements in facing the requests from the world $\ldots$ at this point, from the outside world. (TR, IIg)

Overall school directors, teacher-referents and teachers recognize the importance of a national assessment system. What they criticize is how it is implemented. In fact, the current system often returns a fragmentary experience, perceived as something unrelated to daily school practice, unable to take the peculiarities of each context into account:

INVALSI must develop evaluation tools that are more related to school life, otherwise [this evaluation] might be conceived as an useless thing and the results, rather than being a stimulus for reflection, might be snubbed. (SD, IIg)

I definitely think that we, as a school, have to give ourselves answers about the evaluation system and I think that having a national assessment system is a good thing ideally. I'm not so sure that this is the way, though. (T, Ig) 
I agree that sometimes it can be helpful to ask yourself where you are. However I am absolutely convinced that, since we are dealing with human beings and with completely different contexts, it would be wrong to assign too much value to this test, both in regards to the level of the students and to the preparation provided by their teachers, because depending on the context, the factors are so different and so tricky that an objective test does not effectively reflect the reality anyway. $(\mathrm{T}, \mathrm{Ig})$

\section{THE STUDENT VOICE}

The students involved in the study were attending middle schools (second and third years) and high schools (third year). They had vivid memories of the tests administered during the previous year or were preparing to take the tests scheduled for the current year.

During the focus group interviews, they participated willingly in the study and were pleased to have a chance - often limited or even absent at school - to freely express themselves and share their point of view.

Although their opinions and memories depict many varied experiences, there are some recurring themes which emphasize the impressions gathered in the interviews with school directors and teachers.

\subsection{So much confusion}

Thinking back to their experiences, one of the first observations made by the young interviewees regard the gap perceived between the lessons in the classroom and the INVALSI tests, that seem distant and disconnected from the school program:

INVALSI has nothing to do with the program. (St, IIg)

All the students reported this impression of foreignness and their perplexity. However, there was disagreement and widespread confusion regarding the purpose of this evaluation.

Among the different opinions, the tests are supposed to assess "the general level» (St, IIg), "to evaluate the preparation of students» (St, IIg), to measure their intelligence or their reasoning skills. Only a minority of respondents believe that the tests have statistical value to allow for a comparison among Italian schools on a national scale.

Furthermore, the implicit doubt that these tests could actually have meritocratic repercussions are also voiced by students: according to their 
performance, schools would be divided into first and second classes «with subsidies granted to first class schools» (St, IIg).

\subsection{The lack of information: from teachers to students}

The confusion evident in the students' comments is further evidence of the lack of information that affected the communication processes both inside and outside the school when it comes to the INVALSI tests. The information gap and the incomprehensibility on the training level described by teachers seem to inevitably reflect on the students.

Overall, they report only having received essential information, mostly related to organizational aspects: "they explained the timeframe, the schedule» (St, IIg).

However, there are some differences across the educational levels. In particular, while middle schools teachers devoted more attention to this experience, providing exercises and simulations in order to prepare pupils properly; greater carelessness characterized high schools where the teachers often informed the students about the tests only few days before and in some cases students didn't even receive this information:

The teachers didn't tell us much. They handed us the test and only said: «Here, do it». (St, IIg)

Greater teacher involvement in middle schools might be due to the awareness of the key role played by the INVALSI tests in the final State Exam and the resulting need to prepare students for this decisive milestone.

However, even in those schools that paid more attention to communicating with students, teachers generally didn't explain and clarify the goals and criteria behind the INVALSI evaluation. This is not particularly surprising considering that teachers themselves often declared not to know them.

\subsection{The student questionnaire: unnecessarily invasive}

The information gap and the lack of knowledge about purposes of the INVALSI evaluation contributed to the negative comments regarding the student questionnaire, frequently mentioned by pupils.

Even teachers noticed that students didn't appreciate the questionnaire and blamed its length and monotony.

However, these are not the most critical elements in the eyes of students. In fact, the majority consider the questionnaire useless, pointless and 
too invasive. In particular they criticize some «bad questions» (St, Ig), that touch on personal and sometimes sensitive subjects:

How does [the questionnaire] fit in? Maybe a street cleaner's son is very interested in school, instead a doctor's son doesn't care. I didn't grasp the sense of this questionnaire! (St, IIg)

In the end what does INVALSI care? They should assess us, not the context we live in! (St, IIg)

[The questionnaire is] invasive. It gets too personal, how many books do you have at home? What is your father's job? And your mother's? This doesn't affect how you do on the INVALSI test. (St, IIg)

They ask you things about your private life ... it isn't a nice thing. That is, they also ask you who you live with ... why does INVALSI care about this? (St, IIg)

Sometimes I would like to tell them «mind your own business!». Because ... that is, I'm fine, but maybe [these questions] remind you that your parents split up and you feel bad ... telling [these things] to some official guy who doesn't even know you really pissed me off. (St, IIg)

Only a few students thought the questionnaire could be useful for statistical purposes:

It must be good for something, for some statistics. (St, Ig)

[It enables them] to see the situation of Italian students, more or less. (St, Ig)

Overall these comments confirm the inadequate information that students receive about the purpose of these tests and the rationale behind a statistical study.

Only one student thought the questionnaire was a demonstration of the State's interest regarding Italian students and suggested proposing it «every year, but unrelated to INVALSI, because Italian State is interested in the conditions of the average student and his family. [...] It has nothing to do with INVALSI» (St, Ig).

\subsection{The lack offeedback: "I want to know if I can do it or not"}

The most critical element of this experience in the eyes of the students is the lack of feedback.

In fact, after correction, only some teachers spent time reviewing and commenting on the tests with students or gave feedback about the general performance of the class: 
When they correct them, they always say that [the tests] did not go well, that we made tons of mistakes. (St, Ig)

The Italian teacher, right after correcting the tests, said that she remembered that we had made some mistakes. She told us that at times we slightly disappointed her because the questions were easy. (St, IIg)

Teachers, especially in high schools, did not give any feedback to students. The results that emerged from INVALSI reports were never discussed with students, although many of them would have liked to know the results and receive more detailed feedback. Almost everyone agrees that reviewing the tests and understanding their mistakes would allow them to «see where we stand» and «improve» (St, Ig):

In my opinion it would be helpful to have the answers, that way you can correct what you did wrong. (St, Ig)

The lack of feedback not only annoys students, but also has a very negative impact on their motivation, especially in high schools where these tests are not evaluated. This lack often lead to excessive carelessness and superficiality in dealing with this experience; an attitude which could affect the validity of this assessment:

The general attitude towards these tests is indifference. When they are evaluated, they inevitably become interesting! If you do not evaluate them there is a total lack of interest. I'm sorry I did them badly, but it doesn't make me sleepless all night. If I could do it over, I wouldn't prepare [for INVALSI tests]. (St, IIg)

\subsection{A non-sense experience}

Overall, all these elements contributed to exacerbating the widespread feeling that the tests were a useless, pointless experience:

It was a useless test for me, because I won't draw any personal benefit. (St, IIg) The INVALSI evaluation appears to be a footnote in school life without any tangible impact, a meteor that suddenly appears and quickly vanishes without leaving any trace behind:

They could be useful if we got them back and they told us: «all right, now we'll correct them together», then they would have sense. The way things are, they are an end in themselves! (St, IIg)

It's a school day you throw away. (St, IIg) 
A significant aspect highlighted by students is the deep influence that teachers' attitudes and opinions had on their experience.

In fact, the more critical and uninterested the teachers are, the more the students feel it was a pointless experience. Moreover, as suggested by students themselves, it is difficult to value an experience that is not only little known and «invested with meaning», but which is sometimes even discredited or openly opposed:

It depends on how teachers see it, because if they think it's useless it also becomes useless for us. (St, IIg)

I'd like to mention how our teachers presented [these tests]. After all, they didn't believe in it either. And they conveyed this message to us: «we do it because we have to». (St, IIg)

Even the teachers didn't care if we talked to each other, whereas during the exams as soon as you move they say: «stand still!». They didn't mind, because they considered them useless! (St, IIg)

\section{DisCUSSION: DILEMMAS AND PARADOXES}

The results from this qualitative study highlight some of the reasons behind the resistance and distrust expressed towards the INVALSI tests and the National Evaluation System established in recent years. They also confirm the key role played by organizational, communicational and informational processes.

The INVALSI tests, due to some lacks, negligence and inefficiencies on the procedural level, are often perceived as not only distant from the school experience, but also as an event with limited practical effects. Deprived of meaning, what remains is a bureaucratic compliance, an unavoidable obligation to be fulfilled, a hassle to bear, an ambiguous product of a machine disconnected from the logic and the needs of those who experience school every day directly.

This reveals a deep paradox: the INVALSI tests - conceived as a support and a stimulus for schools to evolve and improve in a national and selfreferential comparison - do not seem able to activate a critical reflection on teaching-learning processes and assessment models within the school.

On the one hand, it is appropriate to recognize that Italian schools lack a deep-rooted culture regarding evaluation and lack a widespread familiarity with standardized tests, as a school director effectively pointed out: «I think the real difficulty is changing the mentality, schools need to change this cultural issue. I mean, everything that concerns the evaluation of the service, the school, even more evidently the teachers, creates discomfort, resist-

\footnotetext{
ECPS Journal - 13/2016

http://www.ledonline.it/ECPS-Journal/
} 
ance, embarrassment» (SD, IIg). On the other hand, as school directors and teachers pointed out, what is criticized is not the establishment of a national assessment system, rather than the modalities and procedural decisions made in its implementation.

The experiences collected in this study seem to mirror the antinomy described in literature between accountability and program evaluation, social control and social development objectives (Ribolzi, Maraschiello, \& Vanetti, 2001; Paletta 2011; Castoldi, 2012). Evaluating to control school productivity does not necessarily trigger reflective processes and improvement, but might be reduced to a simple action of social accountability. Evaluating to improve, however, encourages reversal of the logic typical of accountability systems, involving school actors and paying attention to the meanings that permeate the evaluation experience.

Several authors have discussed the limits of accountability systems that disregard reflective processes within schools and that are merely based on the assessment of student performance and competition among schools - such as teaching-to-test, or the superficial learning induced by an excessive emphasis on ranking and competition (MacBeath \& McGlynn, 2002; Corsini 2008a, 2008b, 2013; Corsini \& Losito, 2013). Therefore, it is essential to go beyond the paradigm based solely on accountability and reinterpret evaluation by adopting a systematic perspective and focusing on process (Mariani, 2010).

The national evaluation system seems currently moving in this direction. In fact, through experimental projects and a recently implemented decree (DPR. 80/2013), the national evaluation system has formally recognized the importance and need to combine internal and external evaluation. This is undoubtedly a positive signal, even more so in light of the paradoxical effects generated by the disconnection between methods, objectives and actions of the national evaluation system and the school itself.

However, the national evaluation system is still taking the first steps in this complex journey, establishing time frames and procedures and identifying the skills and professional profiles that can help schools to mediate and reconcile perspectives and needs inside and outside the school (Pastori, 2014 ), in order to combine external evaluation of products and internal processes of interpretation and self-evaluation in a significant way. This largely depends on the deeper and more significant involvement of schools in their evaluative experiences.

The research participants suggested some actions that would ensure to this experience a greater ecological validity in the school-system, such as meeting the general demand for information and professional development (especially about the test's characteristics and the rationale behind their construction), or providing schools with more accessible and timely results in the restitution 
phase, or supporting school in connecting tests and results with the improvement of the teaching method in order to foster higher level of competences, avoiding the teaching-to-test phenomenon, or not including the tests within the final State Examination (see also Pastori \& Pagani, in corso di stampa).

If INVALSI wants to cease being a stranger, it must learn to enter schools and talk to teachers and students in a language they can understand, showing a genuine interest in knowing and meeting them (Mantovani, 2014). Making national assessment a meaningful experience, an enriching and valuable opportunity in the eyes of school directors, teachers and students is paramount in order to contribute to school improvement and to the development of a shared educational culture of evaluation:

In my opinion, INVALSI is an extraordinary opportunity for change, that can affect the class council ... provided that the Ministry plays its cards right. (T, IIg)

\section{REFERENCES}

Bottani, N., \& Cenerini, A. (2003). Una pagella per la scuola: la valutazione tra autonomia e equità. Trento: Erickson.

Brown, G. T. L., \& Hirschfield, G. H. F. (2008). Students' conceptions of assessment: Links to outcomes. Assessment in Education: Principles, Policy and Practice, 15, 3-17.

Castoldi, M. (2012). Valutare a scuola: dagli apprendimenti alla valutazione di sistema. Roma: Carocci.

Cerini, G. (2012). Una certa idea di valutazione: apprendimenti, insegnanti, scuole, sistema. Faenza: Homeless Book.

Corsini, C. (2008a). Il valore aggiunto in educazione. Roma: Nuova Cultura.

Corsini, C. (2008b). L'impiego del valore aggiunto nella valutazione dell'efficacia scolastica: problemi e prospettive. In G. Domenici \& R. Semeraro (a cura di), Le nuove sfide della ricerca didattica tra saperi, comunità sociali e culture (pp. 605-615). Roma: Monolite.

Corsini, C. (2013). La validità di contenuto delle prove INVALSI di comprensione della lettura. Giornale Italiano della Ricerca Educativa / Italian Journal of Educational Research, 10, 46-61.

Corsini, C., \& Losito, B. (2013). Le rilevazioni INVALSI: a che cosa servono? Cadmo, 2, 55-76.

Czerniawski, G., \& Kidd, W. (2011). The student voice handbook: Bridging the academic/practitioner divide. Bingley, UK: Emerald Group.

Entwistle, N. J., \& Entwistle, A. C. (1991). Contrasting forms of understanding for degree examinations: The student experience and its implications. Higher Education, 22, 205-227. 
Grion, V., \& Cook-Sather, A. (2013). Student voice: prospettive internazionali e pratiche emergenti in Italia. Milano: Guerini.

Hattie, J., \& Timeperley, H. (2007). The power of feedback. Review of Educational Research, 77, 81-112.

MacBeath, J., \& McGlynn, A. (2002). Self-evaluation: What's in it for schools? London: Routledge (trad. it., Trento: Erickson).

Mantovani, S. (2014). Tutor di miglioramento: sfide e complessità di una nuova figura professionale. In M. Faggioli (a cura di), Migliorare la scuola: autovalutazione, valutazione e miglioramento per lo sviluppo della qualità (pp. 219233). Bergamo: Junior.

Mariani, L. (2010). Saper apprendere: atteggiamenti, motivazioni, stili e strategie per insegnare a imparare. Padova: libreriauniversitaria.it.

OECD (2014). PISA 2012. Results in focus: What 15-year-olds know and what they can do with what they know. Retrieved from: http://www.oecd.org/pisa/ keyfindings/pisa-2012-results-overview.pdf

Paletta, A. (2011). Scuole responsabili dei risultati: accountability e bilancio sociale. Bologna: il Mulino.

Pastori, G. (2013). La valutazione a scuola: esperienze e riflessioni di studenti italiani e di altre culture nella scuola italiana. In V. Grion \& A. Cook Sather (a cura di), Student voice: prospettive internazionali e pratiche emergenti in Italia (pp. 179-192). Milano: Guerini.

Pastori, G. (2014). Chi è il Tutor di Miglioramento? Finalità, funzioni, stile e competenze. In M. Faggioli (a cura di), Migliorare la scuola: autovalutazione, valutazione e miglioramento per lo sviluppo della qualità (pp. 233-254). Bergamo: Junior.

Pastori, G., \& Pagani, V. (in corso di stampa). Le prove INVALSI nella scuola: processi organizzativi, comunicativi e informativi nell'esperienza di dirigenti, insegnanti e studenti. Uno studio qualitativo in Lombardia. In P. Landri \& A. Maccarini (a cura di), Uno specchio per la valutazione della scuola: paradossi, controversie, vie di uscita. Milano: FrancoAngeli.

Ribolzi, L., Maraschiello, A., \& Vanetti, R. (2001). L'autovalutazione nella scuola dell'autonomia. Brescia: La Scuola.

Ruddock, J., \& McIntyre, D. (2007). Improving learning through consulting pupils. Teaching and Learning Research Programme. London: Routledge.

Schleicher, A. (2011). Building a high-quality teaching profession: Lessons from around the world. Paris: OECD, doi: http://dx.doi.org/10.1787/ 9789264113046-en.

Struyven, K., Dochy, F., \& Janssens, S. (2005). Students' perceptions about evaluation and assessment in higher education: A review. Assessment \& Evaluation in Higher Education, 30, 331-347. 


\section{Riassunto}

La ricerca "Promuovere la cultura della valutazione nella scuola. L'esperienza delle prove INVALSI nella scuola» condotta tra il 2011 e il 2012 da un team di ricercatori dell'Università degli Studi di Milano-Bicocca ha rilevato rappresentazioni, opinioni e percezioni dei principali attori del contesto scolastico rispetto all'esperienza della valutazione degli apprendimenti operata da INVALSI. Adottando una "prospettiva multivocale», all'interno di ciascuna scuola (n. 16), attraverso interviste individuali e focus group, sono stati esaminati i punti di vista di diversi protagonisti: dirigenti (n. 12), insegnanti di tutti i livelli scolastici (n. 106) - alcuni dei quali referenti per la valutazione INVALSI all'interno dei rispettivi istituti - e studenti di scuola secondaria di primo e secondo grado (n.100) che avevano affrontato tre o quattro volte le prove INVALSI nel corso della loro carriera scolastica. L'ipotesi interpretativa, confermata dalla presente ricerca, ritiene che le procedure organizzative e comunicative messe in atto da INVALSI, prima e durante la somministrazione e correzione delle prove, e soprattutto nella fase di restituzione dei risultati, abbiano delle importanti ricadute sulla percezione della valutazione nazionale nelle scuole, sulle modalità attraverso cui dirigenti e insegnanti propongono le prove agli studenti, e in ultima analisi sull'atteggiamento degli studenti nei confronti delle prove stesse. Le esperienze raccolte sembrano riflettere l'antinomia tratteggiata in letteratura tra "accountability" $e$ "program evaluation", tra obiettivi di controllo sociale e obiettivi di crescita e sviluppo. I risultati evidenziano le complessità insite nel coniugare questi diversi approcci - "accountability" e processi di riflessione e autovalutazione interna alla scuola - in un'ottica sistemica e processuale coerente.

Parole chiave: Prove di valutazione standardizzate, Qualità del sistema scolastico, Ricerca qualitativa, Voce degli insegnanti, Voce degli studenti.

How to cite this Paper: Pastori, G., \& Pagani, V. (2016). What do you think about INVALSI tests? School directors, teachers and students from Lombardy describe their experience [Cosa pensate dei test INVALSI? Dirigenti scolastici, insegnanti e studenti provenienti dalla Lombardia descrivono la loro esperienza]. Journal of Educational, Cultural and Psychological Studies, 13, 97-117. doi: 10.7358/ecps2016-013-past 